\title{
Cationic Ring-Opening Polymerization of 4,5-Dihydro-1,3-oxazol-5-ones to Produce $N$-Alkoxycarbonylated Polypeptides and Its Related Oligomerization
}

\author{
Masatoshi Miyamoto, ${ }^{\dagger}$ Yuji Itoh, Kazuhiro HoriI, ${ }^{*}$ Ryuichi Kanayama, ${ }^{*}$ \\ and Yoshiharu KIMURA \\ Department of Polymer Science and Engineering, Faculty of Textile Science, \\ Kyoto Institute of Technology, Matsugasaki, Sakyo, Kyoto 606, Japan \\ * Department of Chemical and Biochemical Engineering, Faculty of Engineering, \\ Toyama University, Gofuku, Toyama 930, Japan
}

(Received March 28, 1997)

\begin{abstract}
The present paper describes the cationic ring-opening polymerization of 2-alkoxy-4,5-dihydro-1,3-oxazol-5ones derived from L-valine, L-isoleucine, L-leucine with methyl trifluoromethanesulfonate (MeOTf) as the initiator. The polymerization of these oxazolones proceeded successfully below $0^{\circ} \mathrm{C}$ and gave poly $(N$-alkoxycarbonyl- $\alpha$-amino acid $) \mathrm{s}$ in moderate yields. The ease of polymerization was dependent on the 2- and 4-substituents of the oxazolone ring and the combination of bulky groups strongly reduces it. The reaction of 2-ethoxy-4,4-dimethyl-4,5-dihydro-1,3-oxazol-5-one with a catalytic amount of MeOTf did not produce a polymer, but yielded a bicyclic dimer, selectively.

KEY WORDS 2-Alkoxy-4,5-dihydro-1,3-oxazol-5-one / Cationic Ring-Opening Polymerization / Poly $(N$-carboalkoxy- $\alpha$-amino acid)s / Selective Dimerization /
\end{abstract}

Polypeptide consisting of one $\alpha$-amino acid [homopoly $(\alpha$-amino acid) can be prepared by the anionic ringopening polymerization of $N$-carboxy anhydride of $\alpha$ amino acid (NCA). ${ }^{1}$ The previous paper described the preparation of a new polypeptide derivative, $\operatorname{poly}(N$ ethoxycarbonyl-L-valine) (5b), by the cationic ring-opening polymerization of $(S)$-4-isopropyl-2-ethoxy-4,5-dihydro-1,3-oxazol-5-one (1b) (Scheme 1). ${ }^{2}$ This polymerization leads to another route to prepare homopoly $(\alpha-$ amino acid)s since the alkoxycarbonyl groups in $\mathbf{5 b}$ can be removed by basic hydrolysis. ${ }^{3}$ This kind of polymer, an $N$-alkoxycarbonylated polypeptide, has never been known in polymer chemistry or any other fields including biochemistry. Polymer $\mathbf{5 b}$ is soluble in many organic solvents because of the lack of amide hydrogen, which is expected to expand the availability of polypeptide derivatives. ${ }^{1}$

Therefore, it is important to examine whether the present polymerization is applicable to oxazolone monomers prepared from other $\alpha$-amino acids. The present paper describes cationic ring-opening polymerization of 2alkoxy-4,5-dihydro-1,3-oxazol-5-ones having 4-alkyl substituent.

The monomers investigated were oxazolone derivatives of L-valine, L-isoleucine, L-leucine, and 2-aminoisobutyric acid, i.e., (S)-4-isopropyl-(1), (S)-4-(sec-butyl)(2), (S)-4-isobutyl- (3), and 4,4-dimethyl-4,5-dihydro-1,3-

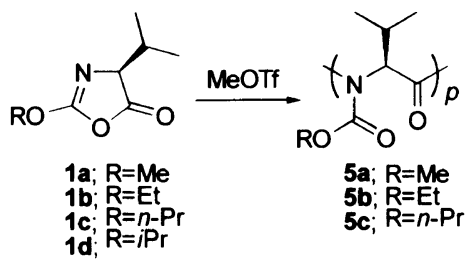

Scheme 1.

† To whom correspondence should be addressed. oxazol-5-ones (4), respectively. They were prepared from the corresponding $N$-alkoxycarbonylated $\alpha$-amino acids and their polymerization with methyl trifluoromethanesulfonate (MeOTf) was investigated.<smiles>[R]OC1=N[C@H](C(C)CC)C(=O)O1</smiles>

2a; $R=M e$
2b; $R=E t$

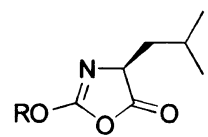

3b

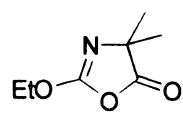

4b

\section{EXPERIMENTAL}

\section{Materials}

The monomers, $(S)$-4-isopropyl-2-methoxy- (1a), $(S)$-2ethoxy-4-isopropyl- (1b), (S)-4-isopropyl-2-propoxy(1c), and (S)-2-isopropoxy-4-isopropyl-4,5-dihydro-1,3oxazol-5-ones (1d), (S)-4-(sec-butyl)-2-methoxy- (2a) and (S)-4-(sec-butyl)-2-ethoxy-4,5-dihydro-1,3-oxazol5-ones (2b), (S)-2-ethoxy-4-isobutyl-4,5-dihydro-1,3oxazol-5-one (3b), and 2-ethoxy-4,4-dimethyl-4,5-dihydro-1,3-oxazol-5-one (4b) were prepared by the cyclization of the corresponding $N$-alkoxycarbonyl $\alpha$-amino acids using dicyclohexylcarbodiimide. ${ }^{4}$ Other reagents and solvents were commercially available, dried by conventional methods, and distilled under nitrogen. The solvents were stored over $3 \AA$ molecular sieves after distillation.

\footnotetext{
Measurements

${ }^{1} \mathrm{H}$ NMR spectra were recorded on a $90 \mathrm{MHz}$ JEOL JNM-FX90Q NMR spectrometer or a $400 \mathrm{MHz}$ JEOL JNM-A400 NMR spectrometer. ${ }^{13} \mathrm{C}$ NMR spectra were recorded on a JEOL JNM-FX90Q NMR spectrometer operated at $22.6 \mathrm{MHz}$ or a Varian Gemini-200 NMR spectrometer operated at $50 \mathrm{MHz}$. IR spectra were ob-
} 
tained on a JASCO IR-810 infrared spectrometer. GPC analysis was performed with a Shodex 880 system using a Shodex AC803 column in chloroform. Optical rotations were measured in chloroform on a Union PM-101 polarimeter at $22^{\circ} \mathrm{C}$.

\section{Typical Procedure for the Polymerization of 4,5-Dihydro-} 1,3-oxazol-5-ones $1-3$

In a test tube equipped with a magnetic stirrer bar and a three-way stopcock were placed $0.200 \mathrm{~g}(1.27 \mathrm{mmol})$ of $1 \mathrm{a}$ and $0.30 \mathrm{~mL}$ of chloroform under nitrogen. The mixture was kept at $-78^{\circ} \mathrm{C}$ and $10 \mathrm{mg}(0.063 \mathrm{mmol})$ of MeOTf was added to the mixture with stirring. The mixture was allowed to react at $-20^{\circ} \mathrm{C}$ for $20 \mathrm{~h}$. The produced polymer, poly $(N$-ethoxycarbonyl-L-valine) (5a), was isolated by precipitation from hexane, washed with hexane, and dried in vacuum. The yield was $0.104 \mathrm{~g}$. The supernatant hexane layer and washings were combined and concentrated with an evaporator. After drying in vacuum, $0.094 \mathrm{~g}(47 \%)$ of oligomeric 5a was additionally obtained.

5a; ${ }^{1} \mathrm{H}$ NMR $\left(\mathrm{CDCl}_{3}\right): 0.6-1.1\left(\mathrm{CH}\left(\mathrm{CH}_{3}\right)_{2}, 6 \mathrm{H}\right)$, $2.4-2.7\left(\mathrm{CH}\left(\mathrm{CH}_{3}\right)_{2}, \quad 1 \mathrm{H}\right), 3.6-3.9 \quad\left(\mathrm{OCH}_{3}, 3 \mathrm{H}\right)$, 5.5-5.7 (NCH, 1H). IR (film) 2955, 2860, 1750, 1698, 1437, 1372, 1260, 1200, 1012, $754 \mathrm{~cm}^{-1}$.

Poly(N-propoxycarbonyl-L-valine) 5c was prepared similarly by the polymerization of $1 \mathrm{c} .{ }^{1} \mathrm{H} \mathrm{NMR}\left(\mathrm{CDCl}_{3}\right)$ : $0.6-1.3\left(\mathrm{CH}_{3}, 9 \mathrm{H}\right), 1.4-2.0\left(\mathrm{OCH}_{2} \mathrm{CH}_{2}, 2 \mathrm{H}\right), 2.3-2.9$ $\left(\mathrm{CH}\left(\mathrm{CH}_{3}\right)_{2}, 1 \mathrm{H}\right), 3.9-4.3\left(\mathrm{OCH}_{2}, 2 \mathrm{H}\right), 5.5-5.8(\mathrm{NCH}$, 1H). IR (KBr) 2957, 2928, 2860, 1745, 1694, 1398, 1308, 1240, 1208, 1172, 1050, $935 \mathrm{~cm}^{-1}$.

Poly( $N$-methoxycarbonyl-L-isoleucine) 6a from $2 \mathbf{2 a}{ }^{1} \mathbf{H}$ NMR $\left(\mathrm{CDCl}_{3}\right): 0.6-1.1\left(\mathrm{CH}_{2} \mathrm{CH}_{3}\right.$ and $\left.\mathrm{CHCH}_{3}, 6 \mathrm{H}\right)$, 1.5-2.0 $\left(\mathrm{CH}_{2}, 2 \mathrm{H}\right), 2.2-2.5(\mathrm{NCHCH}, 1 \mathrm{H}), 3.6-3.9$ $\left(\mathrm{OCH}_{3}, 3 \mathrm{H}\right), 5.6-5.8(\mathrm{NCH}, 1 \mathrm{H})$. IR (KBr) 2960, 2877, 1756, 1699, 1440,1382, 1280, 1240, 1202, $1154 \mathrm{~cm}^{-1}$.

Poly(N-ethoxycarbonyl-L-isoleucine) $\mathbf{6 b}$ from $\mathbf{2 b}:{ }^{1} \mathrm{H}$ $\mathrm{NMR}\left(\mathrm{CDCl}_{3}\right)$ : $0.7-1.1\left(\mathrm{CHCH}_{2} \mathrm{CH}_{3}\right.$ and $\mathrm{CHCH}_{3}$, $6 \mathrm{H}), 1.1-1.5\left(\mathrm{OCH}_{2} \mathrm{CH}_{3}\right.$ and $\left.\mathrm{CHCHCH}_{2}, 5 \mathrm{H}\right), 2.2-2.7$ $(\mathrm{NCHCH}, 1 \mathrm{H}), 3.9-4.4\left(\mathrm{OCH}_{2}, 2 \mathrm{H}\right), 5.6-5.9(\mathrm{NCH}$, 1H). ${ }^{13} \mathrm{C} \mathrm{NMR}\left(\mathrm{CDCl}_{3}\right): 11.07\left(\mathrm{CHCH}_{2} \mathrm{CH}_{3}\right), 13.68$ $\left(\mathrm{OCH}_{2} \mathrm{CH}_{3}\right), 15.62\left(\mathrm{CHCH}_{3}\right), 24.87\left(\mathrm{CHCH}_{2}\right), 35.05$ $(\mathrm{NCHCH}), 61.42(\mathrm{NCH}), 63.80\left(\mathrm{OCH}_{2}\right), 153.80(\mathrm{COO})$, $170.6(\mathrm{NCOCH})$. IR (KBr) 2960, 2935, 2875, 1752, 1700 , 1380, 1298, 1260, 1237, 1195, $1020 \mathrm{~cm}^{-1}$.

Poly(N-ethoxycarbonyl-L-leucine) $\mathbf{7 b}$ from $\mathbf{3 b}:{ }^{1} \mathrm{H}$ NMR $\left(\mathrm{CDCl}_{3}\right): 0.7-1.0\left(\mathrm{CH}\left(\mathrm{CH}_{3}\right)_{2}, 6 \mathrm{H}\right), 1.2-1.4$

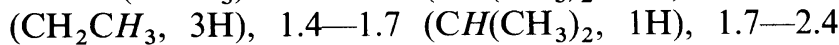

$\left(\mathrm{NCHCH}{ }_{2}, 2 \mathrm{H}\right), 4.0-4.4\left(\mathrm{OCH}_{2}, 2 \mathrm{H}\right), 5.0-5.4(\mathrm{NCH}$, 1H). IR (KBr) 2960, 2885, 1742, 1702 (s), 1473, 1388, $1373,1294,1210,1025,777 \mathrm{~cm}^{-1}$.

\section{Dimerization of 2-Ethoxy-4,4-dimethyl-4,5-dihydro-1,3- oxazol-5-one $\mathbf{4 b}$}

1-Ethoxy-8-ethoxycarbonyl-4,4,7,7-tetramethyl-2,5,8oxadiazabicyclo[3.3.0] octane-3,6-dione (8) was obtained as a viscous liquid by the reaction of $\mathbf{4 b}$ with a catalytic amount of MeOTf and the subsequent treatments described above; ${ }^{1} \mathrm{H}$ NMR $\left(\mathrm{CDCl}_{3}\right): 1.27(\mathrm{t}, J=7.0 \mathrm{~Hz}$, $\left.\mathrm{C}^{5} \mathrm{OCH}_{2} \mathrm{CH}_{3}, 3 \mathrm{H}\right), 1.33\left(\mathrm{t}, \mathrm{J}=7.1 \mathrm{~Hz}, \mathrm{CO}_{2} \mathrm{CH}_{2} \mathrm{CH}_{3}\right.$, $3 \mathrm{H}), 1.53\left(\mathrm{~s}, \mathrm{CH}_{3}, 3 \mathrm{H}\right), 1.61\left(\mathrm{~s}, \mathrm{CH}_{3}, 3 \mathrm{H}\right), 1.64\left(\mathrm{~s}, \mathrm{CH}_{3}\right.$, $3 \mathrm{H}), 1.72\left(\mathrm{~s}, \mathrm{CH}_{3}, 3 \mathrm{H}\right), 3.51\left(\mathrm{q}, J=7.0 \mathrm{~Hz}, \mathrm{C}^{5} \mathrm{OCH}_{2}\right.$, $2 \mathrm{H}), 4.29\left(\mathrm{q}, J=7.1 \mathrm{~Hz}, \mathrm{CO}_{2} \mathrm{CH}_{2}, 2 \mathrm{H}\right) .{ }^{13} \mathrm{C} \mathrm{NMR}$ $\left(\mathrm{CDCl}_{3}\right): 14.27\left(\mathrm{CO}_{2} \mathrm{CH}_{2} \mathrm{CH}_{3}\right), 14.34\left(\mathrm{C}^{5} \mathrm{OCH}_{2} \mathrm{CH}_{3}\right)$, $22.30\left(\mathrm{C}^{4} \mathrm{CH}_{3}\right), 22.64\left(\mathrm{C}^{4} \mathrm{CH}_{3}\right), 23.72\left(\mathrm{C}^{7} \mathrm{CH}_{3}\right), 24.92$ $\left(\mathrm{C}^{7} \mathrm{CH}_{3}\right), 60.34\left(\mathrm{C}^{5} \mathrm{OCH}_{2}\right), 61.22\left(\mathrm{CO}_{2} \mathrm{CH}_{2}\right), 62.27\left(\mathrm{C}^{7}\right)$, $64.14\left(\mathrm{C}^{4}\right), 114.86\left(\mathrm{C}^{1}\right), 151.02\left(\mathrm{NCO}_{2}\right), 174.09\left(\mathrm{C}^{3}\right)$, and $173.83\left(\mathrm{C}^{6}\right)$. IR (liquid film) 2986, 1813, 1744, 1329, $1098 \mathrm{~cm}^{-1}$. Exact Mass $(\mathrm{M}+1)$ Found ; 315.1556, Calcd for $\mathrm{C}_{14} \mathrm{H}_{13} \mathrm{~N}_{2} \mathrm{O}_{6} ; 315.1560$.

\section{RESULTS AND DISCUSSION}

\section{Ring-Opening Polymerization of $\mathbf{1}$}

The preceding paper showed that the cationic ringopening polymerization of $\mathbf{1 b}$ produces poly $(N$-ethoxycarbonyl-L-valine) $\mathbf{5 b} .^{2}$ The polymerization of other three monomers derived form L-valine, $(S)$-4-isopropyl-2-methoxy- (1a), (S)-4-isopropyl-2-propyloxy-(1c), and 2-isopropoxy-4-isopropyl-4,5-dihydro-1,3-oxazol-5-ones (1d) was further examined to investigate the influence of the 2-alkoxy substituent of 1 on the ring-opening polymerization. The results are shown in Table I and are compared with those for the polymerization of $\mathbf{1 b}$.

The cationic ring-opening polymerization of $\mathbf{1 a}$ with $5 \mathrm{~mol} \%$ of MeOTf proceeded in chloroform at $0^{\circ} \mathrm{C}$. After reprecipitation into hexane, a ring-opening polymer (5a) was obtained in $21 \%$ yield. The GPC analysis showed that the number average molecular weight $\left(M_{n}\right)$ of $5 \mathbf{a}$ was 2900 . At $-20^{\circ} \mathrm{C}$, the polymerization of 1 a gave the polymer in $52 \%$ yield whose $M_{n}$ was 4100 . The monomer consumption was complete in each run. The reason for the low yields was because the lower molecular weight part of 5 was soluble in hexane, the reprecipitant. Actually, considerable amounts of oligomers were recovered from the supernatant layers. ${ }^{5}$

Table I. Cationic ring-opening polymerization of $\mathbf{1}^{\mathrm{a}}$

\begin{tabular}{|c|c|c|c|c|c|c|c|}
\hline \multirow{3}{*}{1} & \multirow{3}{*}{$\frac{\text { Temp }}{{ }^{\circ} \mathrm{C}}$} & \multicolumn{6}{|c|}{ Product } \\
\hline & & \multirow[b]{2}{*}{5} & Yield & \multirow{2}{*}{$M_{n}^{\mathrm{b}}$} & \multirow{2}{*}{$M_{w} / M_{n}{ }^{\mathrm{b}}$} & \multirow{2}{*}{$\mathrm{DP}^{\mathrm{b}}$} & \multirow{2}{*}{$\frac{[\alpha]_{\mathrm{D}}^{22 \mathrm{c}}}{\circ}$} \\
\hline & & & $\%$ & & & & \\
\hline $1 \mathbf{a}$ & 0 & $5 \mathbf{a}$ & 21 & 2900 & 1.28 & 17 & -102 \\
\hline $1 \mathrm{a}$ & -20 & $5 \mathbf{a}$ & 52 & 4100 & 1.35 & 26 & -104 \\
\hline $1 b^{d}$ & 0 & $5 b$ & 25 & 4400 & 1.49 & 26 & -107 \\
\hline $1 b^{d}$ & -20 & $\mathbf{5 b}$ & 40 & 6100 & 1.54 & 36 & -97 \\
\hline $1 c$ & 0 & $5 c$ & 7 & 2800 & 1.44 & 15 & -171 \\
\hline 1c & -20 & $5 c$ & 30 & 4200 & 1.24 & 23 & -176 \\
\hline
\end{tabular}

${ }^{\mathrm{a}}$ With MeOTf $\left([\mathrm{M}]_{0} /[\mathrm{I}]_{0}=20\right)$ in chloroform for $20 \mathrm{~h}$. ${ }^{\mathrm{b}}$ Determined from GPC with polystyrene standards. ${ }^{\mathrm{c}}$ Measured in chloroform at $[\mathrm{C}]=1 \mathrm{gdL}^{-1} \cdot{ }^{\mathrm{d}}$ Data from ref 2 . 


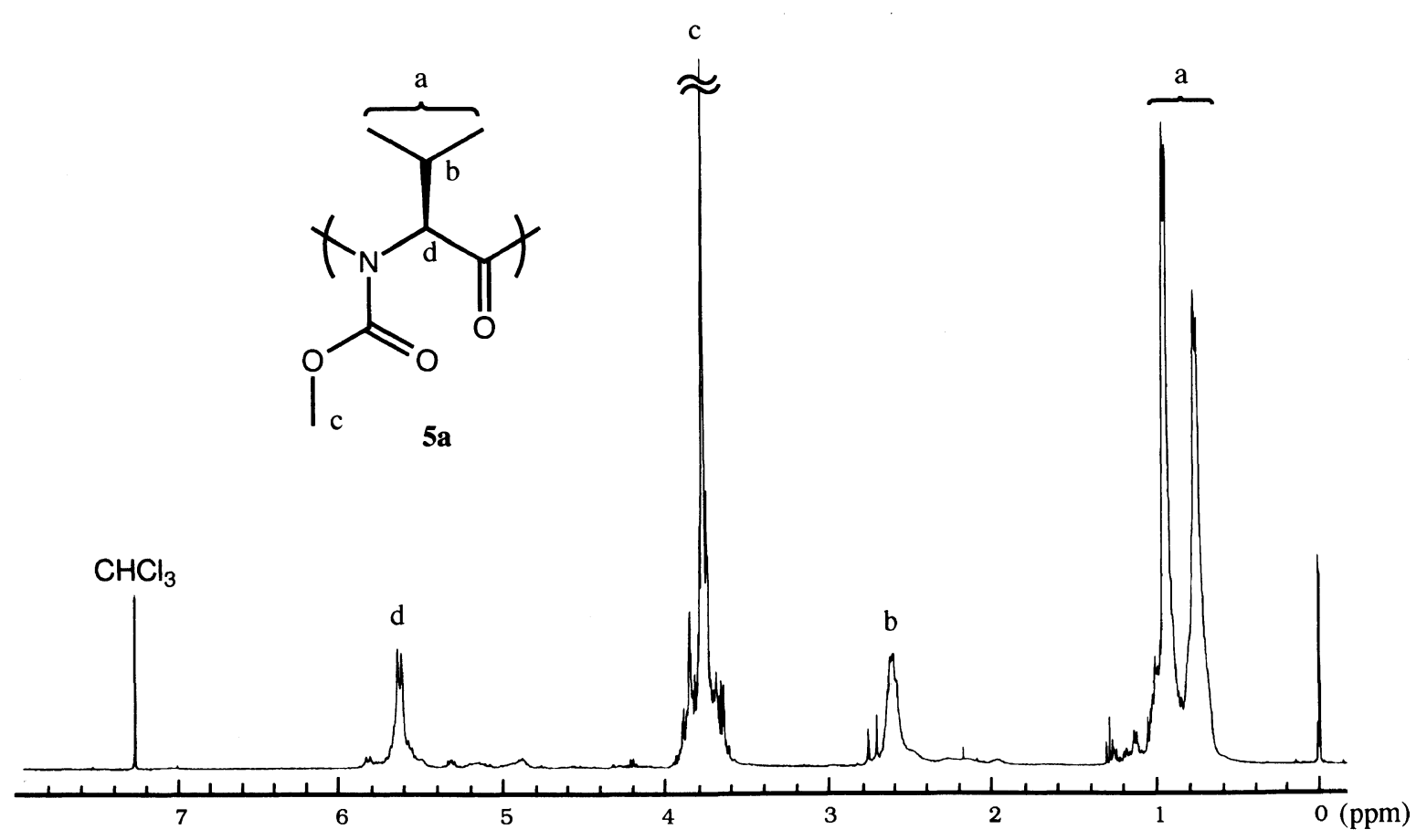

Figure 1. $400 \mathrm{MHz}^{1} \mathrm{H}$ NMR spectrum of $5 \mathbf{a}\left(\mathrm{CDCl}_{3} / \mathrm{TMS}\right)$.

Initiation

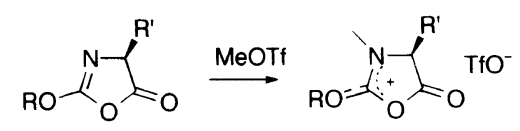

Propagation

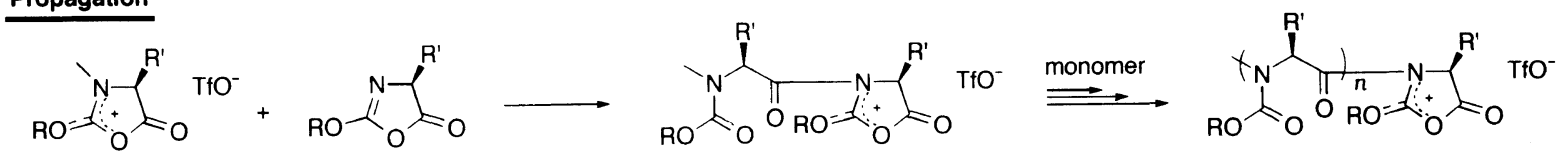

\section{Chain-transfer}
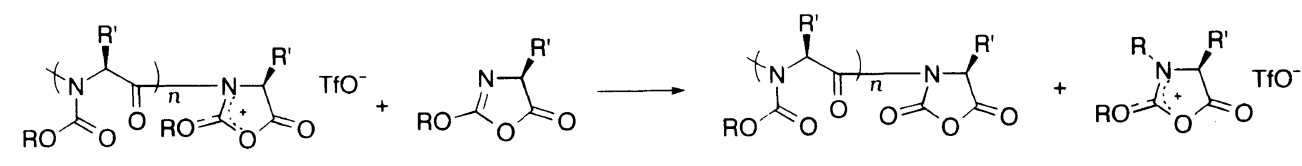

Scheme 2.

The structure of the resulting polymer 5a was identified as $\operatorname{poly}(N$-methoxycarbonyl-L-valine) from spectroscopic analyses. Figure 1 shows the $400 \mathrm{MHz}{ }^{1} \mathrm{H}$ NMR spectrum of the polymer prepared at $-20^{\circ} \mathrm{C}$. The main signals in the figure, indicated by a-d, are ascribed to the protons of $N$-methoxycarbonyl-L-valine unit. Two small singlets at $\delta 2.69$ and 2.78 are ascribed to $\mathrm{N}-\mathrm{CH}_{3}$ protons at the initiating end: the splitting will be due to the presence of syn- and anti-conformers. DP of the polymer could be estimated as 27 from the integral ratio of these two peaks to the peak b, assumpting that each polymer molecule has one methyl group at the initiating end. This value agrees with that estimated from GPC analysis with polystyrene calibration (26). Contrary to this coincidence, the polymerization of $\mathbf{1}$ is considered to be non-living since the study on the polymerization of $\mathbf{1 b}$ shows that it accommodates chain transfer caused by attack of the monomer to the exo-methylene carbon at the propagating end (Scheme 2). ${ }^{2}$

The molecular weight of $5 \mathbf{a}$ was generally lower than 5 b prepared under similar conditions. The exo-methyl carbon at the propagating end of $\mathbf{5 a}$ is attacked by the monomer more frequently than the corresponding exomethylene carbon in the case of $\mathbf{5 b}$ is. Other weak signals observed in Figure 1 are ascribed to the terminal groups or to the penultimate unit, although no detailed assignment has been made.

The polymerization of 2-alkoxy-2-oxazoline accommodates a similar chain transfer caused by the attack to the exo-alkoxy carbon of the propagating end. Chaintransfer is significantly suppressed by changing the alkoxy moiety of the monomer from ethoxy to isopropyloxy 
Table II. Cationic ring-opening polymerization of $\mathbf{2}^{\mathrm{a}}$

\begin{tabular}{|c|c|c|c|c|c|c|c|c|}
\hline \multirow{3}{*}{ Monomer } & \multirow{3}{*}{$\frac{\text { Temp }}{{ }^{\circ} \mathrm{C}}$} & \multirow{3}{*}{$\frac{\text { Time }}{\mathrm{h}}$} & \multicolumn{6}{|c|}{ Product } \\
\hline & & & \multirow[b]{2}{*}{6} & \multirow{2}{*}{$\frac{\text { Yield }}{\%}$} & \multirow{2}{*}{$M_{n}^{\mathrm{b}}$} & \multirow{2}{*}{$M_{w} / M_{n}^{\mathrm{b}}$} & \multirow[b]{2}{*}{$\mathrm{DP}^{\mathrm{b}}$} & {$[\alpha]_{\mathrm{D}}^{22 \mathrm{c}}$} \\
\hline & & & & & & & & $\circ$ \\
\hline $2 a$ & 0 & 20 & $\mathbf{6 a}$ & 53 & 2500 & 1.50 & 15 & -123 \\
\hline $2 a$ & -20 & 20 & $6 a$ & 59 & 3000 & 1.45 & 18 & -145 \\
\hline $2 a$ & -40 & 20 & $6 a$ & 5 & 3700 & 1.20 & 22 & $-\mathrm{d}$ \\
\hline $2 \mathbf{a}$ & -40 & 100 & $6 a$ & 56 & 3500 & 1.41 & 20 & -92 \\
\hline $2 \mathbf{b}$ & 0 & 20 & $\mathbf{6 b}$ & 22 & 2100 & 1.93 & 11 & -135 \\
\hline $2 b$ & -20 & 20 & $6 b$ & 25 & 4300 & 1.26 & 23 & -136 \\
\hline $2 b$ & -20 & 100 & $\mathbf{6 b}$ & 43 & 4300 & 1.23 & 23 & -118 \\
\hline $2 b$ & -40 & 20 & $6 b$ & 12 & 6800 & 1.28 & 37 & $-\mathrm{d}$ \\
\hline $2 \mathbf{b}$ & -40 & 100 & $\mathbf{6 b}$ & 51 & 6900 & 1.44 & 37 & -143 \\
\hline
\end{tabular}

${ }^{\mathrm{a}}$ With MeOTf $\left([\mathrm{M}]_{0} /[\mathrm{I}]_{0}=20\right)$ in chloroform. ${ }^{\mathrm{b}}$ Determined from GPC with polystyrene standards. ${ }^{\mathrm{c}}$ Measured in chloroform $\left([\mathrm{C}]=1 \mathrm{~g} \mathrm{dL}{ }^{-1}\right)$. d Not measured.

according to the general tendency in $S_{\mathrm{N}} 2$ reaction. ${ }^{6}$ In the present case, no polymerization of $\mathbf{1 d}$ took place at $\leq 0^{\circ} \mathrm{C}$. At room temperature, the reaction of $1 \mathbf{d}$ with $5 \mathrm{~mol} \%$ of MeOTf gave an oligomeric product in $32 \%$ yield $\left(M_{n}=460\right)$. Since 1d has two bulky substituents near the nitrogen atom, its nucleophilicity is reduced, which significantly retards polymerizability.

The cationic ring-opening polymerization of $1 \mathrm{c}$ proceeded at $0^{\circ} \mathrm{C}$ in a similar manner and gave poly $(N$ propoxycarbonyl-L-valine) (5c), although the yield of the hexane insoluble product was poor $(7 \%)$. Much oligomer $(91 \%)$ was recovered from the supernatant hexane layer. $M_{n}$ s were 2800 (the hexane insoluble part) and 850 (the soluble part). The polymerization of $1 c$ carried out at $-20^{\circ} \mathrm{C}$ yielded the hexane insoluble part in $30 \%$ yield $\left(M_{n}=4200\right)$, which accommodated the by-production of hexane soluble oligomer in $66 \%$ yield $\left(M_{n}=1200\right)$.

The yield of $\mathbf{5 c}$ was generally lower than those of $\mathbf{5 a}$ and $\mathbf{5 b}$ examined under the same conditions. This indicates the relatively low polymerizability of 1c, ascribed to the steric effect caused by the propyloxy and isopropyl substituents. These results prove that the 2 -alkoxy substituent significantly influences the polymerization of $\mathbf{1}$ and ethoxy is the most suitable 2-substituent.

\section{Ring-Opening Polymerization of $\mathbf{2}$}

The cationic ring-opening polymerization of $\mathbf{2}$ gave poly $(N$-alkoxycarbonyl-L-isoleucine) (6) in a similar manner (Scheme 3 and Table II). In the polymerization of $(S)$-4-isobutyl-2-methoxy-4,5-dihydro-1,3-oxazol-5one (2a) carried out at $0^{\circ} \mathrm{C}$ or $-20^{\circ} \mathrm{C}$ for $20 \mathrm{~h}$, poly $(N$ methoxycarbonyl-L-isoleucine) 6a was obtained as the hexane insoluble product in moderate yield. At $-40^{\circ} \mathrm{C}$, the polymerization of $\mathbf{2 a}$ was slow and produced the hexane insoluble $6 \mathrm{a}$ in $5 \%$ yield after $20 \mathrm{~h}$, while the yield increased to $56 \%$ after $100 \mathrm{~h}$. The coincidence of the $M_{n}$ of these samples shows chain transfer during polymeriza-

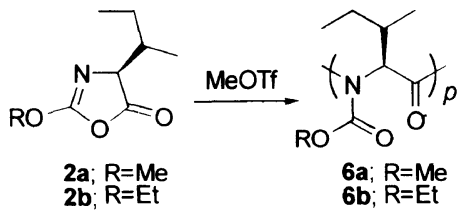

Scheme 3. tion. The same has been observed in the polymerizations of $\mathbf{2 b}$ at $-20^{\circ} \mathrm{C}$ and at $-40^{\circ} \mathrm{C} .^{2}$

The polymer yield of $\mathbf{6 b}$ was generally lower than that of 6a carried out under the same conditions, indicating a lower rate of polymerization. However, the molecular weight of $\mathbf{6 b}$ was generally higher than the corresponding 6a sample, reflecting the difficulty of chain transfer. $M_{n}$ of $\mathbf{6 b}$ increased from 2100 to 6900 as the polymerization temperature decreased from $0^{\circ} \mathrm{C}$ to $-40^{\circ} \mathrm{C}$. This was also observed in the polymerization of $\mathbf{1}$.

\section{Ring-Opening Polymerization of $\mathbf{3}$}

The polymerization of (S)-4-(sec-butyl)-2-ethoxy-4,5dihydro-1,3-oxazol-5-one 3b gave poly $(N$-ethoxycarbonyl-L-leucine) (7b) similarly (Scheme 4). No clear relationship between the polymerization temperature and the polymer molecular weight was observed, although the yield was generally higher than those of the homologues, $\mathbf{5 b}$ and $\mathbf{6 b}$, prepared under the same conditions.

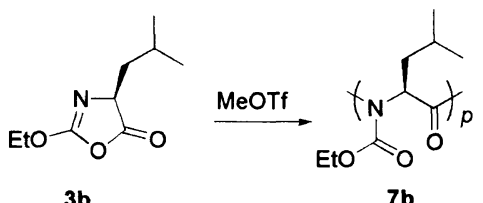

Scheme 4.

Polymer $7 \mathbf{b}$ showed relatively low optical rotation, $[\alpha]_{\mathrm{D}}=-3 \sim-23^{\circ}$ at $22^{\circ} \mathrm{C}$, possibly indicating racemization during the polymerization. However, a comparison of the $\mathrm{CD}$ spectrum of $\mathbf{7 b}$ measured in chloroform with that of $\mathbf{5 b}$ clearly showed the chiral carbon to be preserved in the polymer (Figure 2). The hyper structure of $\mathbf{7 b}$ could not be evaluated from the CD spectrum since the measurement was limited at $\lambda>220 \mathrm{~nm}$ because of the disturbance by the solvent's UV absorption: $7 \mathbf{b}$ was not soluble in the solvents commonly used for CD measurement, water, trifluoroethanol, and dioxane.

The effects of the 4-substituents on the polymerizability of the oxazolone monomers can be evaluated by comparison of the data shown in Tables I-III. The monomer having the isobutyl substituent $\mathbf{3}$ has higher reactivity toward the cationic polymerization in comparison with the others having the secondary alkyl 4-sub- 


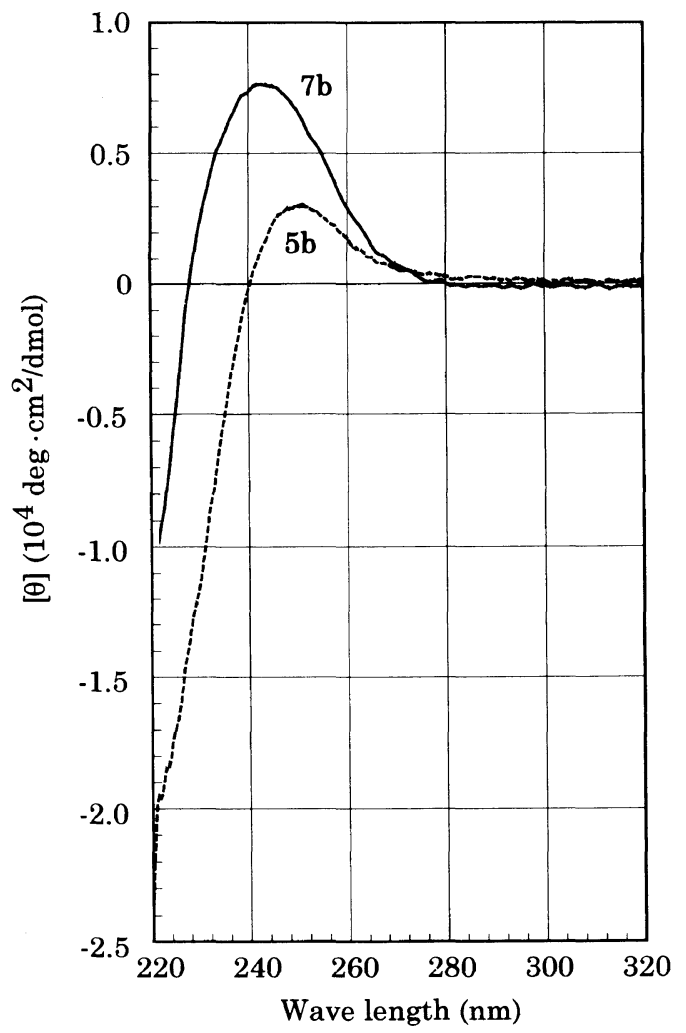

Figure 2. CD spectra of $\mathbf{5 b}$ and $\mathbf{7 b}$ measured in chloroform ([monomer unit $]=7.4 \mathrm{mM}$ ) at $25^{\circ} \mathrm{C}$.

Table III. Ring-opening polymerization of $3 \mathbf{b}^{\mathbf{a}}$

\begin{tabular}{|c|c|c|c|c|c|c|}
\hline \multirow{2}{*}{ Temp } & \multirow{2}{*}{ Time } & \multicolumn{5}{|c|}{$7 b$} \\
\hline & & Yield & \multirow{3}{*}{$M_{n}^{\mathrm{b}}$} & \multirow{3}{*}{$M_{w} / M_{n}^{\mathrm{b}}$} & \multirow{3}{*}{$\mathrm{DP}^{\mathrm{b}}$} & \multirow{2}{*}[\alpha]{$_{D}^{22}$} \\
\hline \multirow[t]{2}{*}{${ }^{\circ} \mathrm{C}$} & \multirow[t]{2}{*}{$\%$} & & & & & \\
\hline & & $\%$ & & & & 0 \\
\hline 0 & 20 & 77 & 11000 & 1.71 & 59 & -13 \\
\hline-20 & 20 & 60 & 8900 & 1.83 & 48 & -24 \\
\hline-20 & 100 & 90 & 6900 & 1.41 & 37 & -8 \\
\hline-40 & 20 & 44 & 4100 & 1.45 & 22 & -3 \\
\hline-40 & 100 & 91 & 6800 & 1.83 & 37 & -8 \\
\hline
\end{tabular}

${ }^{a}$ With MeOTf $\left([\mathrm{M}]_{0} /[\mathrm{I}]_{0}=20\right)$ in $\mathrm{CHCl}_{3}$. ${ }^{\mathrm{b}}$ Determined from GPC with polystyrene standards. ${ }^{\mathrm{c}}$ Measured in chloroform at $[\mathrm{C}]=$ $1.0 \mathrm{~g} \mathrm{dL}^{-1}$.

stituent, 1 and 2, supposingly due to a steric reason.

The influence of 4-substitent on the ring-opening polymerization of oxazolone monomers will become clearer when derivatives of glycine are used for polymerization. Such derivatives could not be prepared despite repeated trials. Even the preparation of alanine derivatives failed. Since oxazolones are prepared by the intramolecular cyclization of $N$-alkoxycarbonylated $\alpha$-amino acid, lack of a bulky substituent at the 4-position may strongly reduce cyclization.

It is of importance to clarify whether the polymerization of $1-4$ proceeds with or without racemization. In the pervious study we observed that the absorbance in the CD spectra of $\mathbf{5 b}$ became stronger as the polymerization temperature rose, perhaps, indicating racemization at elevated temperature. The progress of racemization is also suspected in the present cases, although no concrete evidence has been indicated yet.
Table IV. Selective dimerization of $\mathbf{4 b}$ catalyzed by MeOTf ${ }^{\mathbf{a}}$

\begin{tabular}{|c|c|c|c|c|}
\hline \multirow{3}{*}{ Solvent } & \multirow{2}{*}[4\mathbf{b}]{$_{0}$} & \multicolumn{3}{|c|}{ Product } \\
\hline & & Yield & \multirow{2}{*}{$M_{n}^{\mathrm{b}}$} & \multirow{2}{*}{$M_{w} / M_{n}^{\mathrm{b}}$} \\
\hline & & $\%$ & & \\
\hline $\mathrm{CHCl}_{3}$ & 5.0 & 88 & 290 & 1.01 \\
\hline $\mathrm{CHCl}_{3}$ & 21 & 62 & 280 & 1.03 \\
\hline $\mathrm{CH}_{3} \mathrm{CN}$ & 21 & 62 & 290 & 1.07 \\
\hline $\mathrm{CH}_{3} \mathrm{NO}_{2}$ & 21 & 61 & 300 & 1.07 \\
\hline $\mathrm{PhCH}_{3}$ & 21 & 47 & 300 & 1.03 \\
\hline $\mathrm{PhCN}$ & 22 & 65 & 300 & 1.02 \\
\hline $\mathrm{PhNO}_{2}$ & 22 & 65 & 310 & 1.03 \\
\hline
\end{tabular}

${ }^{\text {a At }} 0^{\circ} \mathrm{C}$ for $20 \mathrm{~h} .{ }^{\text {b }}$ Determined from GPC with polystyrene standards.

\section{Selective Dimerization of $\mathbf{4 b}$}

The introduction of two substituents at the 4-position of the oxazolone ring is expected to retard ring-opening polymerizability. Thus, the polymerization of a 4,4-disubstututed oxazolone monomer, 2-ethoxy-4,4-dimethyl5,6-dihydro-1,3-oxazol-5-one (4b) was examined.

The reaction of $\mathbf{4 b}$ with MeOTf was expected to give $\operatorname{poly}(N$-ethoxycarbonyl- $\alpha$-aminoisobutyric acid). However, it gave no polymeric material, but an oligomer whose molecular weight determined from GPC was around 300 . The resulting product had very narrow molecular weight distribution $(<1.07)$ as shown in Table IV. The yield of the oligomer depended on polymerization conditions, while molecular weight was not. The selective production of a dimer was expected from these results since the molecular mass of $\mathbf{4 b}$ is 157.17 (exact mass is 157.074). Exact mass analysis showed that the molecular weight of the product was 314.148 , exactly twice that of $\mathbf{4 b}$, which means that it did not contain any unit derived from the initiator. ${ }^{1} \mathrm{H},{ }^{13} \mathrm{C}$, and DEPT NMR spectroscopies as well as IR and mass analyses revealed that the structure of this dimer was 1-ethoxy8-ethoxycarbonyl-4,4,7,7-tetramethyl-2,5,8-oxadiazabicyclo[3.3.0] octane-3,6-dione, 8 (Scheme 5).

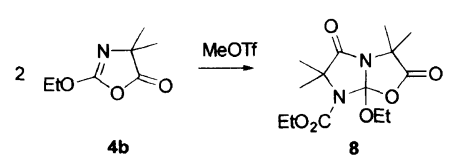

Scheme 5.

Figure 3 shows ${ }^{13} \mathrm{C}$ NMR spectrum of 8 . A peak at $\delta 114.86$ (peak $\mathrm{f}$ ) is due to the quaternary carbon at the bridge head. Signals due to the four methyl carbons located at the $\beta$-position of carbonyl groups appears independently at around $\delta 22.3-24.9$ (peak b, $\mathrm{b}^{\prime}$ ), indicating the magnetic environment of these four methyl carbons are different from one another. These findings support the bicyclic structure of $\mathbf{8}$. Assignments for the other main signals appeared in the spectrum are shown in the figure.

Selective dimerization was considered to proceed as shown in Scheme 6. First, an oxazolonium species 9 was produced by reaction of $\mathbf{4 b}$ with MeOTf. Attack of $\mathbf{4 b}$ to the 5-position of this salt will lead to propagation. However, dimethyl substituents at the 4-position make the intramolecular cyclization advantageous. The carba- 

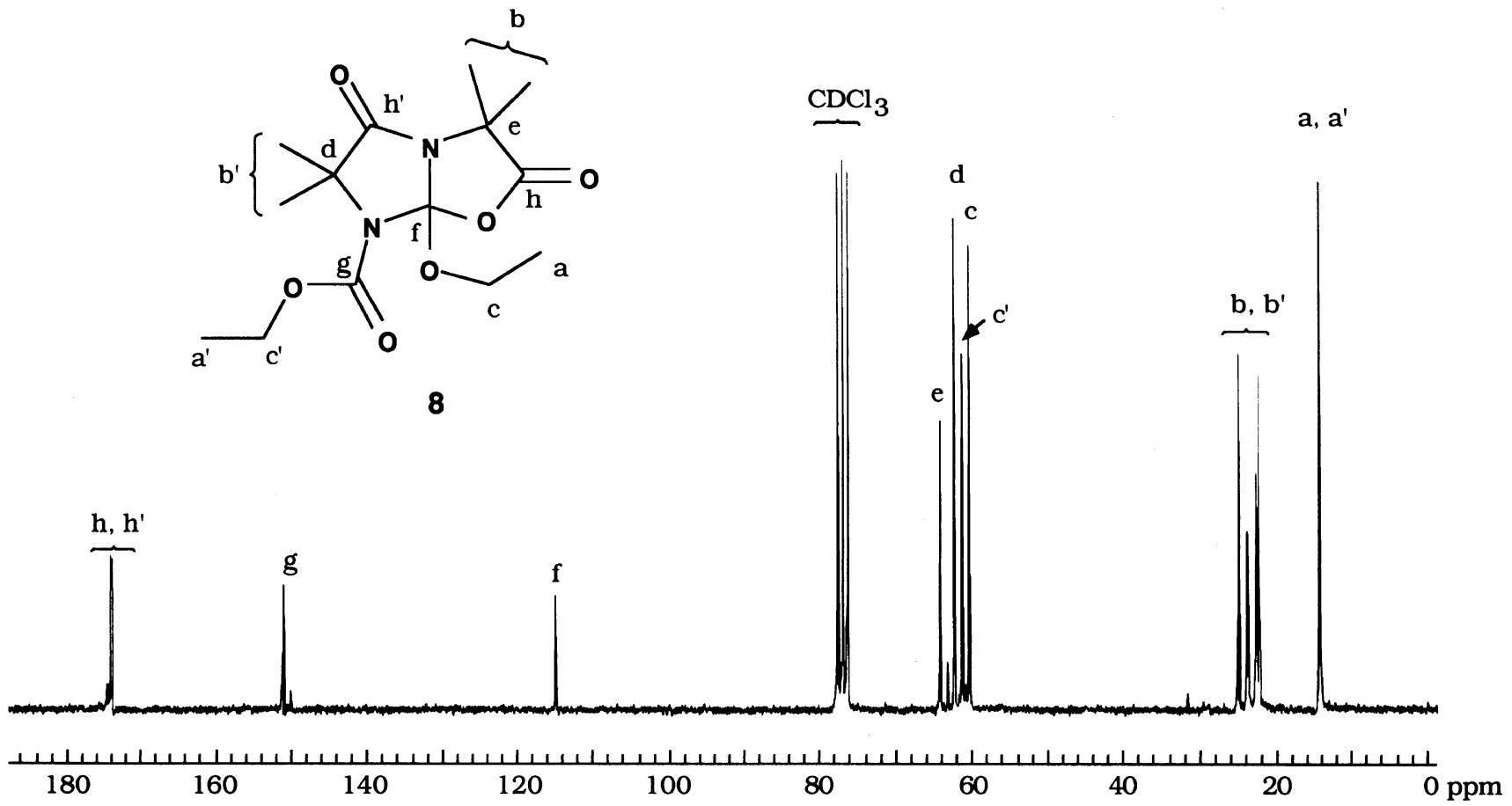

Figure 3. $50 \mathrm{MHz}{ }^{13} \mathrm{C} \mathrm{NMR}$ spectrum of $8\left(\mathrm{CDCl}_{3} / \mathrm{TMS}\right)$.
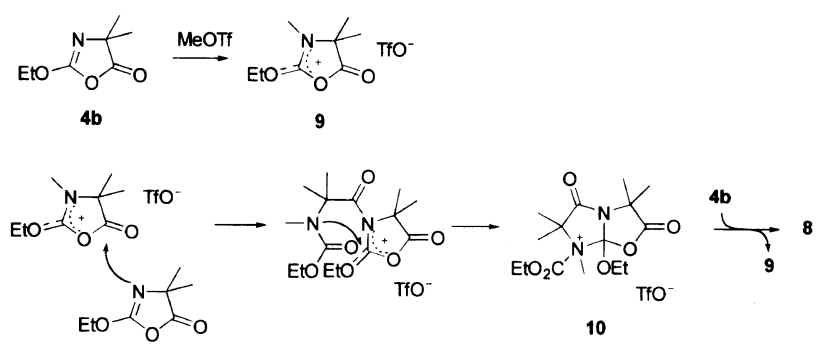

Scheme 6.

mate nitrogen of the dimeric species $\mathbf{1 0}$ thus attacks the 2-position of the oxazolonium ring of it intramolecularly to form a bicyclic quaternary ammonium compound, 11. An $S_{\mathrm{N}}$ 2-type attack of $\mathbf{4 b}$ to the $N$-methyl carbon of $\mathbf{1 1}$ gives 8 and reproduces 9.

Although the reaction of 1d with MeOTf gave an oligomeric product, GPC analysis of the product showed that it was a mixture of oligomers and the production of an 8-like bicyclic dimer was not observed from IR and NMR spectroscopies. Probably, this cyclization is unique to 4,4-disubstituted oxazolone monomers.

It may be concluded that only oxazolone monomers having one 4-substituent are available for ring-opening polymerization. The unsubstituted monomers can hardly prepared and the disubstituted monomers do not polymerize. Natural $\alpha$-amino acids except glycine has one substituent on their $\alpha$-carbon. Therefore, they can be converted to oxazolones except for alanine and proline. Selection of the 2-alkoxy substituent strongly influences on reactivity and the functional group in the 4-substituent may interfere with polymerization, a problem to be solved in the polymerization of oxazolone monomers.

\section{REFERENCES AND NOTES}

1. H. R. Kricheldorf, " $\alpha$-Aminoacid- $N$-Carboxy-Anhydrides and Related Heterocycles," Springer-Verlag, Berlin, 1987.

2. M. Miyamoto, Y. Itoh, C. W. Lee, Y. Kimura, R. Kanayama, and K. Horii, Macromolecules, 30, 1863 (1997).

3. M. Miyamoto, Y. Itoh, and Y. Kimura, unpublished results.

4. a) N. L. J. Benoiton and F. M. F. Chen, Can. J. Chem., 59, 384 (1981). b) F. M. F. Chen, K. Kuroda, and N. L. J. Benoiton, Synthesis, 230 (1979).

5. The yields of hexane soluble oligomers were $79 \%\left(M_{n}=1000\right.$, $\left.M_{w} / M_{n}=1.29\right)$ and $47 \%\left(M_{n}=1100, M_{w} / M_{n}=1.34\right)$ in the runs carried out at 0 and $-20^{\circ} \mathrm{C}$, respectively.

6. M. Miyamoto, K. Aoi, M. Morimoto, Y. Chujo, and T. Saegusa, Macromolecules, 25, 5878 (1992). 